\title{
The European Respiratory Society evaluates its 2013-2018 strategic plan implementation
}

\author{
Giovanni Battista Migliori ${ }^{1}$ European Respiratory Society (ERS) Secretary \\ General 2013-2016, Elisabeth Bel² ERS President 2014-2015, \\ Guy Joos ${ }^{3}$ ERS President 2016-2017, Mark Elliott ${ }^{4}$ ERS Treasurer 2013-2016, \\ Gernot Rohde ${ }^{5}$ ERS Education Council Chair 2014-2017, Stephen T. Holgate ${ }^{6}$ \\ ERS Science Council Chair 2013-2016, Christina Gratziou ${ }^{7}$ ERS Advocacy \\ Council Chair and Secretary for EU Affairs 2015-2018, Dan Smyth ${ }^{8}$ European \\ Lung Foundation Chair 2014-2017, Mina Gaga ${ }^{9}$ ERS President \\ 2017-2018, Carlos Robalo Cordeiro ${ }^{10}$ ERS Secretary General 2016-2019, \\ Otto C. Burghuber ${ }^{11}$ ERS Treasurer 2016-2019, Guy Brusselle ${ }^{12,13}$ ERS Science \\ Council Chair 2016-2019, Fernando Martin-Burrieza ${ }^{14}$, Werner Bill ${ }^{15}$, \\ Betty Sax ${ }^{16}$ and Jørgen Vestbo ${ }^{17}$ ERS President 2015-2016
}

\begin{abstract}
Affiliations: ${ }^{1}$ WHO Collaborating Centre for TB and lung diseases, Fondazione S. Maugeri, Care and Research Institute, Tradate, Italy. ${ }^{2}$ Dept of Respiratory Medicine, Academic Medical Center, University of Amsterdam, Amsterdam, The Netherlands. ${ }^{3}$ Dept Respiratory Medicine, Ghent University Hospital, Ghent Belgium. ${ }^{4}$ Respiratory Medicine, St James's University Hospital, Leeds, UK. ${ }^{5}$ Dept of Respiratory Medicine, Maastricht University Medical Center, Maastricht, The Netherlands. ${ }^{6}$ Clinical and Experimental Sciences, Faculty of Medicine, Southampton University Foundation Trust, Southampton, UK. ${ }^{7}$ University Respiratory Medicine Unit, Evgenidio Hospital, Athens, Greece. ${ }^{8}$ European Lung Foundation, UK. ${ }^{9} 7$ th Respiratory Medicine Dept, Athens Chest Hospital, Athens, Greece. ${ }^{10}$ Centre of Pneumology, Coimbra University Hospital, Coimbra, Portugal. ${ }^{11}$ Dept of Respiratory and Critical Care Medicine and Ludwig Boltzmann Institute for COPD and Respiratory Epidemiology, Otto Wagner Hospital Vienna, Vienna, Austria. ${ }^{12}$ Dept of Respiratory Medicine, Ghent University Hospital, Ghent, Belgium. ${ }^{13}$ Depts of Epidemiology and Respiratory Medicine, Erasmus Medical Center, Rotterdam, The Netherlands. ${ }^{14}$ ERS Executive Director 2012-2015, European Respiratory Society, Lausanne, Switzerland. ${ }^{15}$ ERS Deputy Executive Director/Director of Finance and Administration, European Respiratory Society, Lausanne, Switzerland. ${ }^{16}$ ERS Head of the Executive Office, European Respiratory Society, Lausanne, Switzerland. ${ }^{17}$ Centre for Respiratory Medicine and Allergy, The University of Manchester and University Hospital South Manchester NHS Foundation Trust, Manchester, UK.
\end{abstract}

Correspondence: Giovanni Battista Migliori, WHO Collaborating Centre for TB and Lung Diseases, Fondazione Salvatore Maugeri, Care and Research Institute, via Roncaccio 16, 21049, Tradate, Italy.

E-mail: giovannibattista.miglioriafsm.it

$@$ ERSpublications

Mid-term evaluation of the 2012-2018 European Respiratory Society strategy implementation http://ow.ly/WKhxk

In July 2013 the European Respiratory Society (ERS) developed its 2013-2018 strategic plan to serve its members better and achieve its mission objectives (table 1) [1]. The outcomes of the previous 2006-2007 Strategy Meeting [2] summarising the ERS pillars (figure 1) and the recently published ERS Presidential plans were used as background material [3-5].

The mid-term strategy implementation review was held on October 21, 2015 in Amsterdam, The Netherlands. It involved the ERS Leadership represented by the members of the Management Group (figure 2), the body that replaced the previous Steering Committee as per the newly approved ERS Constitution and Bylaws $[6,7]$,

Received: Dec 142015 | Accepted after revision: Dec 162015

Conflict of interest: F. Martin-Burrieza, W. Bill and B. Sax are employees of the European Respiratory Society. Further disclosures can be found alongside the online version of this article at erj.ersjournals.com

Copyright @ERS 2016 
as well as the ERS Office represented by the ERS Executive Director on behalf of an internal ERS Office Strategy Review Task Force. Input from the Assemblies was requested during the 2015 ERS International Congress in Amsterdam and was taken into consideration during the discussion.

The aims of the review were to: 1) evaluate the implementation status on each of the strategic decisions with recommendations on action items; 2) discuss, based on the status report, further actions related to budgetary and long-range planning considerations; and 3) ensure that what the ERS has committed to deliver to the membership is indeed accomplished.

The review was also aimed at delivering the following outcomes.

1) An annual ERS internal booklet produced by the ERS Office summarising, in brief, the essential points of the budget for the incoming fiscal year and additional long-range planning (starting with the 2016/2017 budget).

2) An ad hoc excerpt of the status of the Strategy Implementation to be included in the ERS Annual Report, with an update on the implementation of the strategy (starting with the 2015/2016 Annual Report).

3) A timetable for further ad hoc strategic Management Group meetings on selected priority topics (Congress, science/research/publication, education, advocacy and governance) to be organised between 2016 and 2018 in view of the next ERS strategic review.

The review was prepared using the same methodology as the Strategic Plan and was chaired by the ERS President and moderated by the ERS Secretary General, with the support of the ERS Executive Director, the Director of Finance and the Head of the Executive Office, who provided the necessary details on the documentation to be discussed.

The eight strategic areas for discussion were: 1) remaining European or going global; 2) expanding membership; 3) coordinating with other societies; 4) strengthening science; 5) improving education; 6) improving publications; 7) coordinating and enhancing advocacy; and 8) organisational changes to put in practice the decisions taken.

\section{Strategic decision 1: remaining European or going global?}

The core elements defined for the discussion of strategic decision 1 were:

- Create a "magnet effect";

- Share expertise and materials worldwide;

- Promote international involvement into the ERS International Congress;

- Further develop the ERS International Congress programme.

There was agreement that ERS is properly implementing its "magnet effect" considering the outcomes of both the Congresses and the membership programme (see strategic decision 2). The ERS International Congresses in Munich (Germany) and Amsterdam were extremely successful both in terms of scientific programme (5506 and 5421 submitted abstracts, respectively) and attendance (21948 and 23292 registered participants, respectively).

TABLE 1 Summary of the main future directions of the European Respiratory Society (ERS)

1) ERS will maintain its European character but will adhere to activities that will result in its evolution as a global "magnet" leading to international membership and participation in its activities

2) ERS will adopt a simple and affordable membership fee scheme to foster increased membership numbers

3) ERS will launch the Fellowship of the ERS (FERS) programme

4) ERS will support the establishment of a strong world federation of respiratory societies involved in global respiratory health

5) ERS, through its Scientific Committee, will restructure its Assemblies

6) ERS Scientific and Educational Activities ("School") Councils will develop a joint plan

7) ERS will explore the development of a research agency

8) ERS will re-organise its advocacy strategy centred around the Advocacy Committee and ELF for Patients

9) ERS will tune its corporate business model and will undertake the necessary rationalisation of offices and staff

10) ERS will establish a corporate marketing plan

11) ERS will adjust its governance/information technology/finance and communications operational functions to enable implementation of strategy committee decisions

ELF: European Lung Foundation. Reproduced from [1] with permission from the publisher. 
FIGURE 1 The three pillars of the European Respiratory Society.

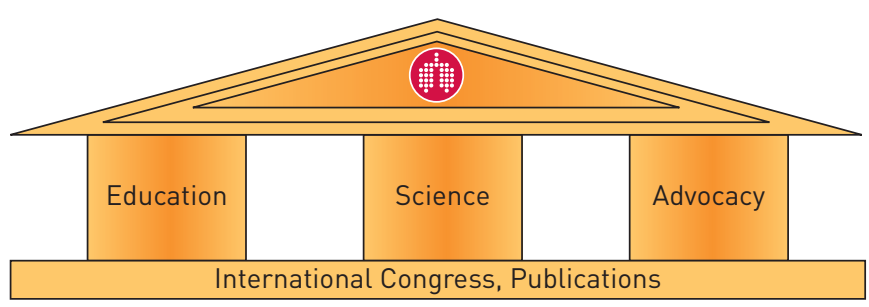

The Management Group recommended that the Science and Education Council fine-tune the international involvement in terms of both Chairs and Speakers, via the ERS International Congress Programme Committee, as much as possible. The sessions translated into Chinese, Spanish/Portuguese and Russian in Amsterdam were successful and will be repeated in 2016 with the addition of a session in French. The Science Council, in collaboration with the Management Group and the Executive Committee, will develop, based on the experience gained, criteria and modalities to embed these special sessions into the Congress programme without compromising on its quality, and taking into consideration the voice of the partner societies and the different activities (e.g. Postgraduate courses) that are going on in parallel.

Overall, as the International Congress remains the key ERS event the Management Group decided to plan a specific meeting in the future to discuss opportunities to further improve the ERS International Congress.

The implementation of the strategic decision was approved.

\section{Strategic decision 2: expanding membership}

The core elements defined for the discussion of strategic decision 2 were:

- Increase membership;

- Support national societies;

- Launch the "Fellowship of the ERS" (FERS) programme.

The ERS has developed agreements with European societies and several non-European regional and national societies; agreements have been signed with 159 societies in 45 countries. The progression in the number of members is summarised in figure 3.

The Management Group agreed that neither the number of members nor the revenue generated by the Membership Programme represent the true value of ERS membership, but the contacts generated from the new members and the possible interactions initiated by each member are the genuine ERS objectives.

The Management Group valued the existing collaborations with partner societies, both at the scientific and educational level (see strategic decisions 4 and 5), and at the level of specific activities requested by partners (e.g. collaboration on spirometry and tuberculosis elimination in Latin America).

The Management Group also confirmed the need to maintain the planned approach to decide on collaborations, based on Management Group and Executive Committee and budget discipline.

FIGURE 2 The mid-term European Respiratory Society strategy meeting in Amsterdam, The Netherlands.

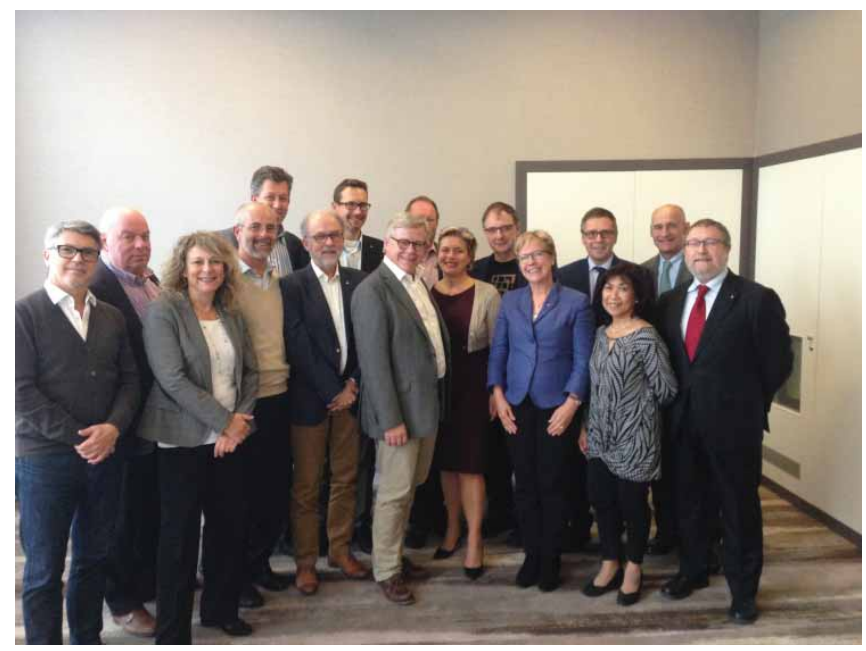




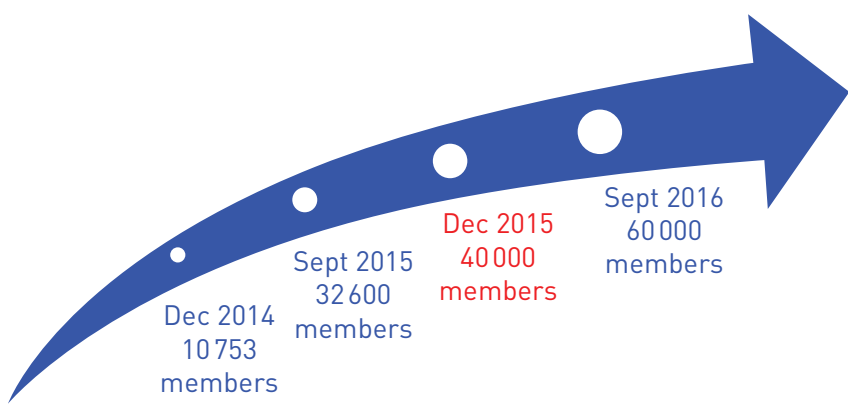

FIGURE 3 European Respiratory
Society membership progression
from 2014 to 2016 .

The FERS programme, aimed at recognising outstanding contributions to respiratory research, education and clinical practice, was successfully launched at the ERS International Congress in Munich (127 founding FERS members) and was continued in Amsterdam (27 new FERS members).

The implementation of the strategic decision was approved.

Strategic decision 3: coordinating with other societies

The core elements defined for the discussion of strategic decision 3 were:

- Foster ongoing cooperation with the European Society of Cardiology (ESC), the World Health Organization (WHO), the American Thoracic Society (ATS), the American College of Chest Physicians (CHEST), and the European Chronic Diseases Alliance (ECDA);

- Support the Forum of International Respiratory Societies (FIRS) and the Alliance for Biomedical Research in Europe (BioMed) Alliance.

The importance of emphasising a unified action to promote global respiratory health through the different collaborations was confirmed by the Management Group; this includes continued collaboration within FIRS. In Europe, the collaboration with the BioMed Alliance will continue in order to promote the importance of clinical and translational research and to influence decision makers in the European Union [8].

Last, but not least, the collaboration with WHO is considered strategic. At present different agreements are in place with their European office in Copenhagen (Denmark) on the tuberculosis Consilium [9-11], and their office in Geneva (Switzerland) on eHealth/mHealth $[12,13]$ and on noncommunicable diseases.

The implementation of the strategic decision was approved.

\section{Strategic decision 4: strengthening science}

The core elements defined for the discussion of strategic decision 4 were:

- Embed basic and translational science into ERS activities;

- Launch the ERS Research Agency;

- Reorganise the Assemblies.

Reconfirming the key role of science (basic, translational and clinical, research) as a major pillar of the ERS, the progress achieved by integrating science with clinical activities within the International Congress was recognised by the Management Group.

The White Paper (which aims to describe the activities, structure and finance model of a Research Agency) has been approved by the Executive Committee, enabling more actual discussions on the launch of an agency [14].

The restructuring of the Assemblies has been discussed at different levels (Group, Assembly and Executive Committee). In view of the different opinions on the best approach to follow, a Working Group will be formed (under the coordination of the Science and Education Councils) to discuss alternative solutions that will then be debated in the Executive Committee before a final decision can be taken.

The implementation of the strategic decision was approved.

\section{Strategic decision 5: improving education}

The core elements defined for the discussion of strategic decision 5 were:

- Implement the International Congress Programme Committee;

- Proceed with the Harmonised Education in Respiratory Medicine for European Specialists (HERMES) activities;

- Re-align the School with education activities within the Educational Council;

- Balance Continuous Professional Development (CPD), Continuous Medical Education (CME) and accreditation. 
The Management Group acknowledged the important progress achieved in integrating Science and Education and implementing the International Congress Programme Committee. HERMES and other educational activities [15-21] have been discussed. In particular, the opportunities offered to collaborate with partner societies in developing HERMES projects in different languages (following the example of the successful examination conducted in Brazil) have been underlined. The coordination through HERMES certification and re-certification in Europe will continue to be discussed.

The implementation of the strategic decision was approved.

\section{Strategic decision 6: improving publications}

The core elements defined for the discussion of strategic decision 6 were:

- Launch a new journal, i.e. ERJ Open Research;

- Further increase the impact factor of the European Respiratory Journal;

- Investigate the possibility of becoming a publishing services company.

ERJ Open Research has been successfully launched as planned. It will hopefully contribute to an increase in the impact factor of the European Respiratory Journal, which is on track to overcome the threshold of 8 in 2016 according to the plan of the current Chief Editor [22-27].

Following a mandate by the Executive Committee, the ERS Office has started exploratory work on the possibilities to transform the present business model of ERS publications into a publishing services company.

The implementation of the strategic decision was approved.

\section{Strategic decision 7: coordinating and enhancing advocacy}

The core elements defined for the discussion of strategic decision 7 were:

- Coordinate with the European Lung Foundation (ELF) to improve advocacy;

- Empower the ERS EU Affairs Office (Brussels, Belgium) to have full remit on advocacy;

- Rationalise partnerships;

- Develop officer-lead advocacy assignments.

Coordinated advocacy is growing, not least through the Healthy Lungs for Life initiative and the collaboration with ELF, as well as the BioMed Alliance and ECDA.

A specific effort may be needed to coordinate the different ERS advocacy activities at different levels (Advocacy Council, ad hoc committees and collaboration with other societies) (see strategic decision 3) and will be further discussed in 2016, possibly through focused discussions with different ERS stakeholders aimed at improving the effectiveness of ERS advocacy based on the change in the ERS that has taken place over the past few years.

The implementation of the strategic decision was approved.

\section{Strategic decision 8: implementing strategic decisions via organisational changes The core elements defined for the discussion of strategic decision 8 were:}

- Recruit a National Society Relationship Manager;

- Fine-tune the ERS Organogram.

The core role of the ERS Office in professionally coordinating the relationship with partner societies was acknowledged by the Management Group. In order to fulfil the ERS goals and objectives and properly implement the strategy, fine-tuning of the ERS Organogram will be discussed under the responsibility of the ERS Executive Director and the remit of the ERS Secretary General.

\section{Conclusions}

Overall, the Management Group recognised that all the activities of the ERS 2013-2018 Strategic Plan have been implemented as expected or have even exceeded expectations. The single major activity needing further discussion is the restructuring of the Assemblies. The newly implemented Working Group involving the Science and Education Councils will start to explore this in detail. Also, more discussions are needed before a final decision is made on the launch of a Research Agency. Ad hoc meetings will be organised in 2016/2017 in recognition of the importance of planning the core activities including the ERS International Congress, science/research/publication, education and governance, and advocacy. 


\section{References}

1 Migliori GB, Rabe KF, Bel E, et al. The European Respiratory Society plans its future: the 2013-2018 strategic plan. Eur Respir J 2014; 43: 927-932.

2 McNee W. The ERS Strategy report. Lausanne, European Respiratory Society, 2007.

3 Blasi F, Barnes PJ, Gaga M, et al. Future Directions for the ERS: presidential plans. Eur Respir J 2013; 42: 875-880.

4 Blasi F, Reichman LB, Migliori GB. Presenting the European Forum for TB innovation: innovative thinking in progressing towards TB elimination in Europe. Eur Respir J 2012; 40: 806-808.

5 Blasi F, Dara M, van der Werf MJ, et al. Supporting TB clinicians managing difficult cases: the ERS/WHO Consilium. Eur Respir J 2013; 41: 491-494.

6 European Respiratory Society. Constitution. www.ersnet.org/images/stories/pdf/Constitution_ADOPTED_in_Amsterdam_2015.pdf Date last accessed: January 21, 2016. Date last updated: October 2015.

7 European Respiratory Society. BYLAWS (adopted in Amsterdam 2015). www.ersnet.org/images/stories/pdf/ Bylaws_ADOPTED_in_AMS.pdf Date last accessed: January 21, 2016. Date last updated: October 2015.

8 Nicod LP, Kamel N, Ward B, et al. ERS is founding member of a new Alliance for Biomedical Research in Europe. Eur Respir J 2011; 38: 237-238.

9 Blasi F, Dara M, van der Werf MJ, et al. Supporting TB clinicians managing difficult cases: the ERS/WHO Consilium. Eur Respir J 2013; 41: 491-494.

10 D'Ambrosio L, Tadolini M, Dupasquier S, et al. ERS/WHO tuberculosis consilium: reporting of the initial 10 cases. Eur Respir J 2014; 43: 286-289.

11 D'Ambrosio L, Tadolini M, Centis R, et al. Supporting clinical management of the difficult-to-treat TB cases: the ERS-WHO TB Consilium. Int J Infect Dis 2015; 32: 156-160.

12 World Health Organization. Digital Health for the End TB Strategy: an Agenda for Action. Geneva, WHO, 2015.

13 Falzon D, Raviglione $\mathrm{M}, \mathrm{Bel} \mathrm{EH}$, et al. The role of eHealth and mHealth in tuberculosis and tobacco control: a WHO/ERS consultation. Eur Respir J 2015; 46: 307-311.

14 Soriano JB, Paton J, Martin-Burrieza F, et al. The ERS Research Agency: the beginning. Eur Respir J 2015 (In press DOI: 10.1183/13993003.02109-2015)

15 Loddenkemper R, Séverin T, Mitchell S, et al. HERMES criteria for accreditation of European Training Centres: overcoming challenges of accreditation. Eur Respir J 2010; 36: 1239-1241.

16 De Backer W, Simonds AK, Horn V, et al. Sleep HERMES: a European training project for respiratory sleep medicine. Eur Respir J 2011; 38: 496-497.

17 Artigas A, Pelosi P, Dellweg D, et al. Respiratory critical care HERMES syllabus: defining competencies for respiratory doctors. Eur Respir J 2012; 39: 1294-1297.

18 Gamarra F, Boffetta P, De Ruysscher D, et al. Thoracic Oncology HERMES syllabus: setting the basis for thoracic oncology training in Europe. Eur Respir J 2013; 42: 568-571.

19 Steenbruggen I, Mitchell S, Severin T, et al. Harmonising spirometry education with HERMES: training a new generation of qualified spirometry practitioners across Europe. Eur Respir J 2011; 37: 479-481.

20 Gappa M, Paton J, Baraldi E, et al. Paediatric HERMES: update of the European Training Syllabus for Paediatric Respiratory Medicine. Eur Respir J 2009; 33: 464-465.

21 Loddenkemper R, Séverin T, Haslam PL. European curriculum recommendations for training in adult respiratory medicine: crossing boundaries with HERMES. Eur Respir J 2008; 32: 538-540.

22 Migliori GB, Soriano JB, Brusasco V, et al. ERJ peer reviewers: does this pillar of the Journal's quality need help? Eur Respir J 2011; 38: 251-252.

23 Dinh-Xuan AT, Brusasco V. The making of the ERJ: behind the scenes and Editors' cut. Eur Respir J 2010; 36 : $4-5$.

24 Dinh-Xuan AT, Brusasco V, Jadwiga A, et al. ERS publications: the flagship and the fleet. Eur Respir J 2012; 40 : 535-537.

25 Humbert M. The ambition of the European Respiratory Journal: chapter 2. Eur Respir J 2014; 43: 1-2.

26 Humbert M, Dinh-Xuan AT, Reeves EL, et al. The ambition of the European Respiratory Journal: chapter 3. Eur Respir J 2015; 45: 1-6.

27 Humbert M, Dinh-Xuan AT, Reeves EL, et al. The ambition of the European Respiratory Journal: chapter 4. Eur Respir J 2016; 47: 1-4. 